Jurnal Indonesia Sosial Teknologi:p-ISSN: 2723 - 6609

e-ISSN :2745-5254

Vol. 3, No.1 Januari 2022

\title{
ANALISIS FRAMING MEDIA KOMPAS DAN NEW YORK TIMES TERHADAP PEMBERITAAN KONFLIK KELOMPOK KRIMINAL BERSENJATA DI PAPUA
}

\author{
Rully Rozano Zarwan ${ }^{1}$, Richie Petroza ${ }^{2}$, Sugi Mukti ${ }^{3}$, Muammar Rafsanjani ${ }^{4}$ \\ Prodi S2 Ilmu Komunikasi, Universitas Islam Kalimantan Muhammad Arsyad Al \\ Banjari ${ }^{1234}$ \\ Email: r_rozindonesia@yahoo.com ${ }^{1}$, paramudabertuah@yahoo.com ${ }^{2}$, \\ ugimukti@gmail.com³ ${ }^{3}$ amrfsnj114@gmail.com ${ }^{4}$
}

\begin{abstract}
Abstrak
Penelitian ini mempermasalahkan Kompas dan New York Times dalam hal pengkonstruksian realitas tentang Kelompok Kriminal Bersenjata di Papua. Hasil penelitian menunjukkan bahwa kedua media berbeda dalam melakukannya. Kompas lebih menekankan pada prestasi pemerintah dalam mengatasi konflik Kelompok Kriminal Bersenjata di Papua. Sedangkan New York Time lebih menekankan pada isu-isu pelanggaran Hak Asasi Manusia terhadap penyelesaian konflik Kelompok Kriminal Bersenjata di Papua. Penelitian ini menggunakan metode analisis framing yang memfokuskan diri ada konstruksi realitas dalam Konflik kelompok Kriminal Bersenjata di Papua. Wacana untuk menunjukkan bahwa isi media massa dipengaruhi oleh pelbagai komponen yang terdapat dalam institusi media itu sendiri. Dari liputan peristiwa-peristiwa Konflik Kelompok Kriminal Bersenjata di Papua adalah realitas atau peristiwa yang dimaknai secara berbeda oleh Kompas dan New York Times, kedua media dipengaruhi oleh karakteristik-karakteristik masing-masing, begitu pula dalam melakukan pengemasan dan pembingkaian berita terhadap realitas Konflik Kriminal Bersenjata di Papua.
\end{abstract}

Kata kunci: Konflik Papua, Framing, Konstruksi Media, Kompas, New York Times.

\section{Abstract}

This research questions Kompas and the New York Times in terms of constructing the reality of Armed Criminal Groups in Papua. The results showed that the two media were different in doing so. Kompas places more emphasis on the government's achievements in overcoming the armed criminal group conflict in Papua. Meanwhile, New York Time put more emphasis on issues of human rights violations in resolving the armed criminal group conflict in Papua. This study uses a framing analysis method that focuses on the construction of reality in the armed criminal group conflict in Papua. Discourse to show that the content of mass media is influenced by various components contained in the media institution itself. From the coverage of the events of the Armed Criminal Group Conflict in Papua, the reality or events are interpreted differently by Kompas and the New York Times, both media are influenced by their respective characteristics, as well as in the packaging and framing of news about the reality of the Armed Criminal Conflict. in Papua. 
Rully Rozano Zarwan, Richie Petroza, Sugi Mukti, Muammar Rafsanjani.

Keywords: Papua conflict, Framing, Media Construction, Kompas, New York Times

\section{Pendahuluan}

Konflik di wilayah Papua yang melibatkan pemerintah Indonesia dengan Kelompok Kriminal Bersenjata (KKB) hingga saat ini masih belum tuntas. Menurut beberapa pendapat, akar masalah yang melatar belakangi konflik tersebut antara lain adalah diskriminasi, rasialisme, pembangunan yang tidak merata, pelanggaran HAM hingga status politik. Bahkan konflik di Papua juga turut menjadi perhatian dunia. Terutama yang berkaitan dengan isu-isu HAM.

Meskipun kontennya sama, nampaknya media lokal dengan media internasional membingkai dan mengkonstruksi konflik di Papua dengan cara yang berbeda. Hal ini dilatarbelakangi berbagai kepentingan ditengah konflik tersebut. Media memiliki fungsi informasi (information) dan mempengaruhi (influence) dalam rangka pembentukan opini publik. Menurut (McQuail, 1994) peranan media massa memiliki kemampuan sebagai alat ideologi karena mampu menarik dan mengarahkan perhatian, membujuk pendapat dan anggapan, mempengaruhi sikap, memberikan status dan mendefinisikan legitimasi serta mendefinisikan realitas. Dalam hal ini sering kali media massa dijadikan sebagai alat berbagai macam kepentingan dalam kehidupan masyarakat sehingga ia menjadi perpanjangan tangan dari berbagai elemen masyarakat. Senada pula menurut McLuhan sebagaimana dikutip oleh (Littlejohn \& Foss, 2010), media merupakan perpanjangan dari pikiran manusia dan beranggapan bahwa kecenderungan utama dalam periode sejarah manapun adalah merupakan suatu pengaruh dari media yang berkuasa pada saat itu. Dengan kata lain suatu fakta bisa menghasilkan suatu feed back berbeda tergantung dari framming yang dilakukan oleh media. Kutipan ini sekali lagi merupakan emphasizing betapa vitalnya peran media dalam membentuk suatu opini dalam sekala massive. Suatu peristiwa dapat ditanggapi secara positif atau negatif kemudian diterjemahkan oleh masyarakat sesuai dengan kenyataan yang sesungguhnya atau tidak sangat bergantung bagaimana media memberitakan peristiwa tersebut, oleh karena itu media massa merupakan alat dari berbagai macam elemen masyarakat dalam menggunakan ideologinya untuk mendapatkan keinginannya baik dalam bidang politik, ekonomi, sosial, agama dan budaya (Muslim, 2013).

Dalam pandangan konstruktivisme, menurut Bennet, sebagaimana dikutip oleh (Hidayat, 1999), media massa bukan hanya sebagai saluran pesan, tetapi sebagai subyek yang mengkonstruksi realitas, pandangan, bias dan pemihakannya. Di sini media massa dipandang sebagai agen konstruksi sosial yang mendefinisikan realitas, pandangan ini menolak pendapat yang menyatakan bahwa media merupakan tempat saluran yang bebas. Begitu pula berita yang di baca dan didengar dari media massa bukan hanya menggambarkan realitas, dan menunjukkan sumber berita tetapi juga konstruksi dari media itu sendiri. Melalui berbagai instrumen yang dimiliki, media ikut membentuk realitas yang tersaji dalam pemberitaan di Indonesia dalam hal ini seperti Konflik di Papua yang semakin memanas beberapa tahun ini. Hal itu bukan menunjukkan realitas 
yang sebenarnya, tetapi menggambarkan bagaimana media ikut berperan dalam mengkonstruksi realitas (Santosa, 2017).

Dalam kasus konflik di Papua setiap surat kabar menyajikan berita sesuai dengan versinya masing-masing. Berita yang disajikan bukanlah realitas yang sesungguhnya karena berita tersebut melalui proses seleksi (Dida, 2017). Apa yang dimunculkan media melalui berita akan memperlihatkan penekanan terhadap satu aspek tertentu, dan juga menyamarkan suatu hal yang tidak dikehendaki oleh media. Hal ini dimungkinkan karena para pemilik dan praktisi media yang berbeda latar belakang dan lingkungan sosial politiknya menjadi salah satu partisipan wacana, bahkan posisinya bisa mewarnai atau mempengaruh partisipasi yang lainnya. Kekuatan media dalam membentuk pesan atau mengembangkan wacana dipengaruhi oleh karakteristik organisasi media dan kerja kaum profesional yang terlibat didalamnya. Menurut Gallagher sebagaimana yang dikutip oleh Gurevetch dalam (Rusadi, 2002) ada dua sumber keterbatasan organisasi media dalam memproduksi berita yaitu dari sumber ekstern dan intern. Hambatan eksternal umumnya bermula pada aspek kepetingan komersial atau politik. Sementara itu hambatan internalnya mengenai rutinitas kinerja para praktisi media itu sendiri, seperti dalam bidang keorganisasiannya atau mengenai komunikator media, yang mempengaruhi dalam proses produksi media yaitu ideologi.

Wacana yang telah terbentuk dalam media massa mempunyai dampak yang sangat penting dalam proses berkembangnya ideologi yang ada pada masyarakat, sehingga hasil perkembangan ideologi akan mempengaruhi pada tingkatan aspek-aspek kepentingan baik dari dalam media massa itu sendiri maupun dari luar. Untuk mengetahui konstruksi media tentang konflik multidimensional di Papua kan diteliti media, yaitu Kompas di Jakarta, dan New York Times di New York, USA. Menurut Hill dalam (Rusadi, 2002), Kompas merupakan media dengan segmen kelas sosial ekonomi menengah keatas dengan latar belakang pendirian berada dalam lingkungan Katolik. New York Times, merupakan media terpopuler di USA dengan margin pasar sebesar 39\% diikuti Washington Post 31\%. Menurut demografi pembaca New York Times 94\% pelanggan media ini adalah dari Partai Demokrat yang sangat kental pengaruh dari latar belakang kristen liberal, katolik, dan sekuler. Hal yang menarik adalah terdapat $16 \%$ pelanggan New York Time Berasal dari luar Amerika, seperti Kanada, Australia, dan negara lain, sehingga common global issues seperti Hak Asasi Manusia dan Isu lingkungan merupakan Hot Selling Property. Berdasarkan latar belakang dan asumsi tersebut di atas maka pemberitaan mengenai konflik di Papua yang kerap bersinggungan dengan isu pelanggaran Hak Asasi Manusia serta isu pemerataan pembangunan, menarik untuk diteliti. Oleh karena itu dalam konteks penelitian ini permasalahan-permasalahan tersebut dirumuskan sebagai berikut, diantaranya adalah: (1) Bagaimana Media Kompas dan New York Times mengkonstruksi realitas atau peristiwa Konflik Kriminal Bersenjata di Papua ? (2) Faktor-faktor apa sajakah yang mempengaruhi Kompas dan New York Times dalam mengkonstruksi realitas atau peristiwa Konflik Kelompok Kriminal Bersenjata di Papua ? Tujuan penelitian ini adalah mengungkap konstruksi realitas Konflik Kriminal Bersenjata dalam media Kompas dan New York Times. Penelitian ini 
diharapkan dapat memberikan kontribusi "pemahaman baru" mengenai cara media massa mengkonstruksi realitas atau mewacanakan Konflik Kelompok Kriminal Bersenjata di Papua. Juga diharapkan mempunyai kegunaan bagi para praktisi memberikan "kesadaran baru" tentang pewacanaan realitas mengenai isu-isu yang bergerak dalam bidang komunikasi massa, media komunikasi massa, dan khususnya para jurnalis dalam mengkonstruksi realitas di balik wacana Konflik Kelompok Kriminal Bersenjata di Papua. Selain itu diharapkan mempunyai kegunaan bagi masyarakat dalam "memberdayakan" pembaca dengan cara menseleksi berita disetiap media dalam mengkonstruksi dan mengkritisi konstruksi realitas wacana tentang Konflik Kelompoj Kriminal Bersenjata di Papua.

Penelitian ini akan mengungkap bagaimana konstruksi realitas media yang berada dibalik wacana konflik Kelompok Kriminal Bersenjata di Papua oleh media. Menurut pandangan konstruktivisme kebenaran dan pengetahuan obyektif sesungguhnya bukan ditemukan, melainkan diciptakan oleh individu. Apa yang dilihat nyata tidak lain merupakan konstruksi pikiran individu dan ia sebenarnya bersifat majemuk, bertentangan, terkonstruksi dan bermakna. Kebenaran adalah persoalan banyaknya informasi dan konstruksi secara mufakat dianggap terbaik atau tercanggih pada saat tertentu.

-Pendekatan Penelitian

Penelitian yang dilakukan dengan melihat konteks permasalahan secara utuh, dengan fokus penelitian pada 'proses' dan bukan pada 'hasil', dengan menggunakan pendekatan Penelitian kualitatif. Penelitian kualitatif adalah sebuah prosedur penelitian yang menghasilkan data deskriptif berupa kata-kata atau tulisan dari orang-orang dan perilaku yang diamati (Moleong, 2012). Adapun jenis Penelitian lebih bersifat deskriptifkualitatif, yaitu berusaha menggambarkan atau menjelaskan secermat mungkin mengenai sesuatu hal atau fenomena, dalam hal ini ingin menggambarkan aspek-aspek apa saja yang mempengaruhi media Kompas dan New York Times dalam mengkonstruksi realitas atau peristiwa Konflik Kriminal Bersenjata di Papua.

\section{Metode Penelitian}

Penelitian ini menggunakan metode analisis framing yang memfokuskan diri ada konstruksi realitas dalam Konflik kelompok Kriminal Bersenjata di Papua. Wacana untuk menunjukkan bahwa isi media massa dipengaruhi oleh pelbagai komponen yang terdapat dalam institusi media itu sendiri. Analisis tekstual ini menggunakan framing model Gamson dan Modigliani. Formula Gamson dan Mondigliani, sebagaimana yang dikutip oleh (Sobur, 2001), menitik beratkan penelitian ini pada penggunaan bahasa yang dipakai media secara mikro. Formula ini dalam meneliti bahasa melalui dua perangkat diantaranya adalah: pertama, depiction visual images. Kedua perangkat penalaran yang terdiri dari root, appeals to principle, concequences, bahasa sangat mempengaruhi konsep framing, karena framing akan ada hal tertentu yang ditonjolkan dan ada juga yang dikorbankan oleh media dalam bentuk realitas media. 


\section{Tabel 1}

Model Framing Gamson dan Modigliani

\section{Frame}

Central Organizing idea for making sense of relevant events, suggesting what is at issue

\begin{tabular}{|c|c|}
\hline $\begin{array}{l}\text { Framing Devices } \\
\text { (Perangkat framing) }\end{array}$ & $\begin{array}{l}\text { Reasioning Devices } \\
\text { (Perangkat Penalaran) }\end{array}$ \\
\hline Reasioning Devices & Roots \\
\hline (Perangkat penalaran) & $\begin{array}{l}\text { Analisis kausal atau } \\
\text { sebab akiba }\end{array}$ \\
\hline Catchapharases & Appeals to principles \\
\hline $\begin{array}{l}\text { Frase yang menarik, kontras menonjol dalam suatu } \\
\text { wacana. Ini umumnya berupa jargon atau slogan }\end{array}$ & $\begin{array}{l}\text { Premis dasar,klaim- } \\
\text { klaim moral. }\end{array}$ \\
\hline Exemplaars & Concequences \\
\hline $\begin{array}{l}\text { Mengaitkan bingkai dengan contoh uraian (bisa teori, } \\
\text { perbandingan) yang memperjelas bingkai. }\end{array}$ & $\begin{array}{l}\text { Efek atau konsekwensi } \\
\text { yang didapat dari } \\
\text { bingkai. }\end{array}$ \\
\hline
\end{tabular}

\section{Depictions}

Penggambaran atau pelukisan suatu isu yang bersifat

konotatif. Depiction ini umumnya berupa kosa kata,

leksikon untuk melabeli sesuatu.

Visual Images

Gambar, grafik citra yang mendukung bingkai secara keseluruhan. Bisa berupa foto, kartun, ataupun grafik untuk menekankan dan mendukung pesan yang ingin disampaikan.

Sumber: Saleh, Rahmat, Potensi Media Sebagai Ruang Publik, Jakarta: Jurnal Penelitian Ilmu Komunikasi, 2004.

\section{Objek Penelitian}

Yang menjadi objek dalam penelitian ini adalah berita-berita mengenai isu Konflik Kelompok Kriminal Bersenjata di Papua di dua media yaitu Kompas dan New York Times. Dari hasil penelusuran ditemukan berita yang dijadikan objek atau bahan penelitian adalah pemberitaan Kompas sebanyak 1 (satu) item. Berita New York Times yang menjadi objek penelitian sebanyak 1 (satu) item. Metode Pengumpulan Data. Dalam penelitian ini pengumpulan data berada pada level teks media. Langkah pertama yang dilakukan oleh peneliti adalah melakukan observasi terhadap Media Kompas dan New York Times. Kemudian menyeleksi teks berita yang memberitakan realitas atau peritiwa Konflik Kelompok Kriminal Bersenjata di Papua. Setelah menyeleksi, maka dipilihlah item berita yang akan menjadi data Primer dan Sekunder dalam penelitian ini.

Analisis data dalam penelitian ini menggunakan analisis Framing Formula Gamson dan Mondigliani, yang memfokuskan penelitian ini pada penggunaan bahasa yang dipakai media secara mikro. 


\section{Hasil dan Pembahasan}

\section{Perbedaan Konstruksi Tentang Konflik Kelompok Kriminal Bersenjata di Papua antara Kompas dan New York Times.}

Media Kompas dan New York Times memberitakan konflik kelompok kriminal bersenjata di Papua pada tahun 2019 hingga tahun 2021. Kemasan yang tampak dalam media menunjukkan adanya hubungan simbol-simbol tertentu yang berbeda didalam mengkonstruksi realitas konflik kriminal bersenjata di Papua, didalam kemasan tersebut didapati adanya beberapa kekuatan hegemoni yang mempengaruhi media Kompas dan New York Times. Faktor-faktor tersebut diantaranya ada faktor internal dan faktor eksternal media. Media Kompas ketika mengemas dan memberitakan wacana konflik Kelompok Kriminal Bersenjata di Papua terdapat adanya praktek hegemoni media, New York Times cenderung membela hak asasi dan kebebasan berpendapat di Papua, sementara Kompas lebih memihak Pemerintah Indonesia. Menurut Fairclough dalam (Mulyana, 2002), salah satu kekuatan hegemoni adalah bagaimana menciptakan cara berpikir atau wacana tertentu yang dominan, yang dianggap benar, sementara wacana lain dianggap salah. Ada suatu nilai atau konsensus yang dianggap memang benar, sehingga ketika ada cara pandang atau wacana lain dianggap sebagai tidak benar. Media disini secara tidak sengaja dapat menjadi alat bagaimana nilai-nilai atau wacana yang dipandang dominan itu disebarkan dan meresap dalam benak khalayak sehingga menjadi konsensus menyimpang. Pemberitaan Kompas dan New York Times mengenai konflik Kelompok Kriminal Bersenjata di Papua, wacana yang dikembangkan sering sekali bahwa untuk penyelesaian konflik di Papua Pemerintah melakukan pendekatan kesejahteraan dan dialog, sebaliknya New York Times membingkai bahwa konflik bersenjata yang terjadi adalah kristalisasi dari isu pelanggaran HAM, ketimpangan pembangunan, dan diskriminasi etnis, hal ini dapat dilihat di bawah ini :

1. Frame Kompas

Kompas membuat berita tentang "Upaya pemerintah redam konflik di Temabagapura" dengan frame sebagai berikut:

Tabel 2

Pemerintah Melakukan Metode Persuasif Untuk Meredakan Konflik di Papua

Judul: Upaya Pemerintah Redam Konflik di Tembagapura (Kompas, 11 Maret 2020)

Frame: Pemerintah Mengedepankan Jalur Dialog Untuk Konflik Papua

\begin{tabular}{|c|c|c|}
\hline \multicolumn{2}{|c|}{ Framing Device } & Reasoning Device \\
\hline \multicolumn{2}{|c|}{ Cathpharases: } & Appeal to Principle: \\
\hline Tito & meminta & Sebanyak $\quad 1.572$ \\
\hline Pemerintah & Daerah Mimika & jiwa telah mengungsi ke \\
\hline
\end{tabular}




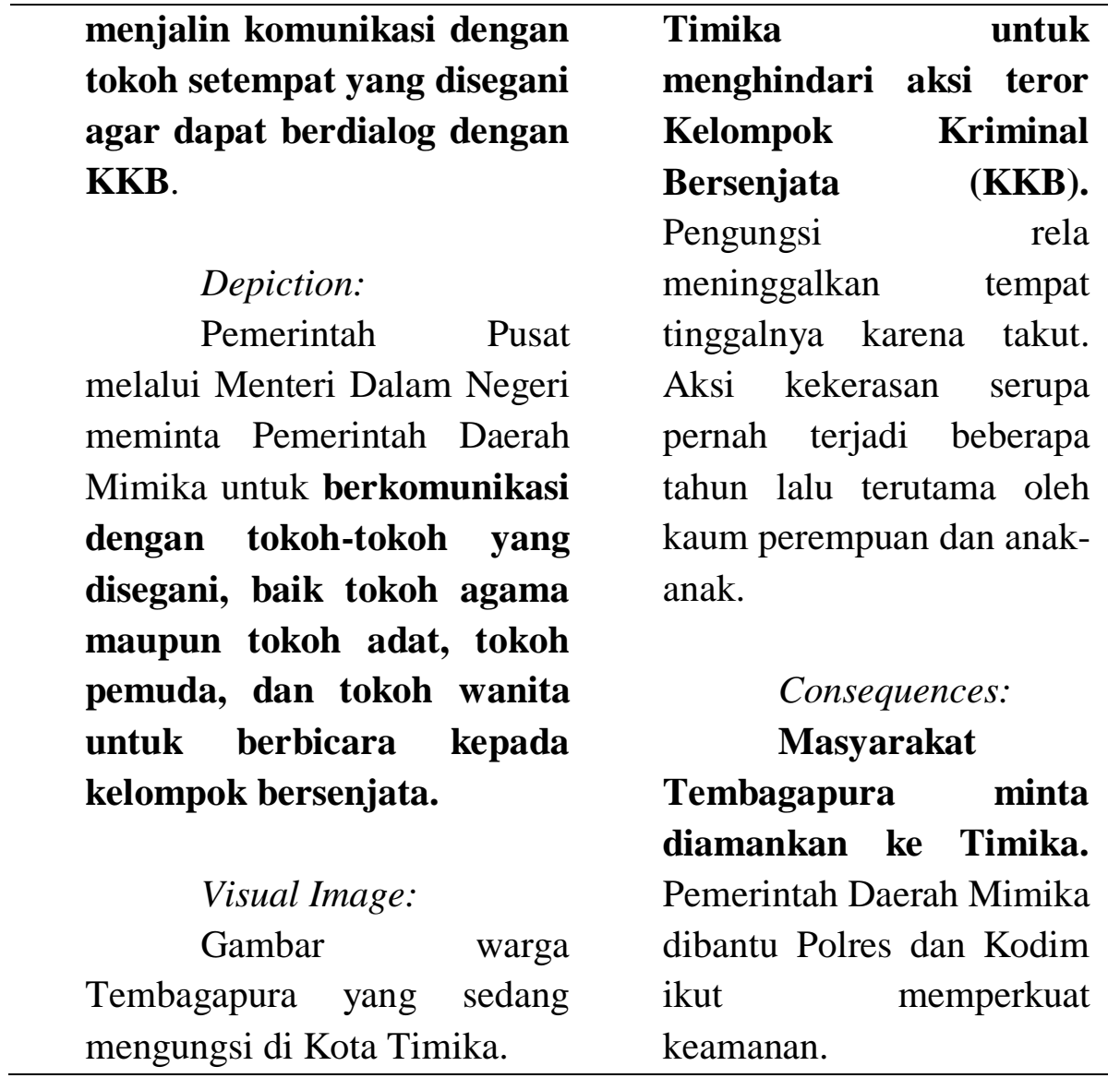

Elemen inti berita (idea element), dalam pandangan Kompas, Pemerintah diwacanakan lebih mengedepankan metode persuasif.

Menteri Dalam Negeri (Mendagri) Tito Karnavian meminta Pemerintah Daerah (Pemda) Mimika dapat memfasilitasi ratusan warga Distrik Tembagapura yang ingin mengungsi ke Timika, Papua pasca-aksi teror Kelompok Kriminal Bersenjata ( KKB).

Tito mengatakan pihaknya sudah berkomunikasi dengan Bupati Mimika Eltinus Omaleng guna membantu pengungsi menuju ke Timika.

Tak hanya itu, Tito meminta Pemerintah Daerah Mimika menjalin komunikasi dengan tokoh setempat yang disegani agar dapat berdialog dengan KKB. "Dari pemda (Mimika) kita minta untuk berkomunikasi dengan tokoh-tokoh yang disegani di sana, baik tokoh agama maupun tokoh adat, tokoh pemuda, tokoh wanita. Berbicara dengan kelompok-kelompok bersenjata itu," katanya.

Menurut Tito, dialog dengan KKB cukup efektif guna meredam aksi teror mereka. Hal itu juga yang pernah dilakukannya saat Tito menjabat Kapolda Papua pada 2012-2014. "Pengalaman saya selaku Kapolda Papua dua tahun, beberapa kali saya bisa melakukan komunikasi-komunikasi dengan mereka, sehingga mereka tidak melakukan aksi kekerasan," ungkap dia.

Perangkat Pembingkai (Framing Devices), dengan menggambarkan Pemerintah mengedepankan proses penyelesaian konflik di papua dengan cara dialog, 
Rully Rozano Zarwan, Richie Petroza, Sugi Mukti, Muammar Rafsanjani.

Kompas membingkai bahwa pemerintah lebih menempuh cara persuasif daripada kekerasan untuk penyelesaian konflik. Kompas menggunakan elemen Cathpharases: Tito meminta Pemerintah Daerah Mimika menjalin komunikasi dengan tokoh setempat yang disegani agar dapat berdialog dengan KKB. Fakta ini diperkuat lagi dengan elemen Depiction yang terdapat sebagai berikut:

Pemerintah Pusat melalui Menteri Dalam Negeri meminta Pemerintah Daerah Mimika untuk berkomunikasi dengan tokoh-tokoh yang disegani, baik tokoh agama maupun tokoh adat, tokoh pemuda, dan tokoh wanita untuk berbicara kepada kelompok bersenjata.

Penggunaan kalimat Pemerintah Pusat meminta Pemerintah Daerah untuk melibatkan tokoh-tokoh masyarakat untuk berbicara kepada kelompok bersenjata ini dimaksudkan untuk mencitrakan positif pemerintah yang menempuh jalur persuasif daripada kekerasan untuk menyelesaikan konflik Kelompok Kriminal Bersenjata di Papua.

Perangkat Penalaran (Reasoning Devices), juga dipakai dalam mengkontraskan upaya pemerintah dalam menempuh jalur persuasif, hal ini dilakukan lewat kemasan Consequence dalam kutipan: Masyarakat Tembagapura minta diamankan ke Timika. Pemerintah Daerah Mimika dibantu Polres dan Kodim ikut memperkuat keamanan. Dan di perkuat lagi dengan Menggunakan elemen Appeal to Principle:

Sebanyak 1.572 jiwa telah mengungsi ke Timika untuk menghindari aksi teror Kelompok Kriminal Bersenjata (KKB). Pengungsi rela meninggalkan tempat tinggalnya karena takut. Aksi kekerasan serupa pernah terjadi beberapa tahun lalu terutama oleh kaum perempuan dan anak-anak.

Penggambaran Kompas dalam frase atau istilah kata Sebanyak 1.572 jiwa telah mengungsi ke Timika untuk menghindari aksi teror Kelompok Kriminal Bersenjata (KKB) memberikan makna negatif dimana Kelompok Kriminal Bersenjata dianggap sebagai kelompok kriminal yang hanya melakukan kekerasan tanpa subtansi tujuan yang jelas. Dalam domain ini, KKB bisa subtitusikan maknanya menjadi pihak pelaku kekerasan. Dari penjelasan diatas dapat di indikasikan bahwa Kompas dalam menyusun dan membingkai berita, adanya aspek kepentingan yang telah dilakukan oleh media massa dan hal ini sesuai dengan teori pendekatan konstruksi

realitas (Berger \& Luckmann, n.d.). Peran media massa ternyata cukup besar mengkonstruksi realitas dalam teks berita berdasarkan pemahaman yang tidak pernah vakum dari kepentingan, keberpihakan dan nilai-nilai. Khalayak pembaca dan pendengar dengan setia memahami tanpa reserve, seolah sebagai realitas yang nyata mereka digiring kedalam frame atau bingkai yang dipasang oleh media.

Dalam konteks penjelasan ini, dengan menggunakan teori "Hirarcy Of Influence"" (Shoemaker \& Reese, 1996), bahwa media dipengaruhi oleh faktor-faktor tertentu diantaranya dipengaruhi oleh faktor eksternal media. Kompas membingkai dan mengemas penyelesaian konflik di Papua, pembingkaian Kompas dipengaruhi 
oleh ideologi politik. Ideologi politik Kompas turut dipengaruhi oleh ideologi media Kompas itu sendiri. Sebagaimana diketahui sejarah berdiri awalnya media Kompas adalah media cetak yang didirikan oleh Partai Katholik berdasarkan masukan dari Jenderal Ahmad Yani untuk menerbitkan surat kabar yang berimbang, kredibel, dan independen untuk menandingi wacana-wacana yang disebarkan oleh Partai Komunis Indonesia saat itu. Dengan izin dari Presien Soekarno maka media kompas yang awalnya bernama "Bentara Rakyat" akhirnya berubah menjadi "Kompas", nama yang langsung diberikan oleh presiden sebagai simbol "penunjuk arah" dan sebagai corong Partai Katholik.

Dalam konstektual politik media kompas sempat mengalami pembredelan atau larangan terbit : 1. Tanggal 1 oktober 1965 terkait dengan kasus G30S/PKI. 2. Tanggal 21 Januari 1978 terkait pemberitaan pencalonan Soeharto sebagai presiden untuk ketiga kalinya dan demo menentang korupsi yang marak. Dalam perjalanannya bisa di asumsikan proses lahirnya media Kompas sendiri mendapat banyak bantuan dan kemudahan ketika masih ada dalam lingkaran Orde Lama dimana Kompas merupakan salah satu proxy yang sengaja diberikan nyawa untuk membendung Hegemoni paham komunisme yang sedang mendapat tempat di hati masyarakat Indonesia kala itu. Berbanding terbalik ketika berada pada rezim pemerintahan berikutnya, order baru. Kompas dianggap sebagai media yang berani mengangkat wacana-wacana yang saat itu dianggap tabu, sebutlah pencalonan Soeharto sebagai presiden untuk kali ketiga yang secara aklamasi selalu memenangkan pemilihan presiden tanpa adanya lawan politik, atau isu-isu korupsi yang sangat rentan diangkat oleh sebuah media cetak saat itu.

Pemerintahan Indonesa saat ini merupakan refleksi dari pemerintahan zaman orde lama dalam artian harfiah saat ini partai penguasa dipimpin oleh anak dari Soekarno yaitu Megawati, yang banyak memiliki jasa lahirnya kompas sebagai sebuah media massa yang bisa bertahan beberapa dekade. Dalam perspektif ini kenetralan Kompas dalam menyoroti berbagai isu terkini terkait dengan kebijakan dan kinerja pemerintah bisa dianggap bias. Salah satu isu yang sampai sekarang menjadi Pekerjaan Rumah setiap rezim adalah konflik di Papua yang notabene memang sudah ada bahkan sejak Kompas itu sendiri lahir.

Wacana konflik papua belum tergambarkan sebagai suatu objek masalah yang bersifat urgent karena pembahasan Kompas untuk solusi konflik bersenjata di Papua hanya sebatas himbauan untuk mediasi, persuasi, dan pendekatan yang masih terasa "tradisional" untuk lingkup masalah yang sangat luas dan kompleks. Sebaliknya dalam framing yang digunakan Kompas untuk memberikan citra positif pada upaya pemerintah yang menggunakan metode persuasif dalam penyelesaian konflik dan membingkai KKB sebagai "aktor" antagonis yang penuh kekerasan terkesan hanya "Make Up" untuk menutupi bahwa memang pemerintah belum mempunyai solusi konkrit untuk konflik di Papua atau ada hidden agenda yang memang sengaja dipelihara untuk kepentingan kelompok tertentu mengingat begitu besarnya potensi alam di Papua. Sebagai contoh Wacana untuk privatisasi PT. Freeport yang sudah 
Rully Rozano Zarwan, Richie Petroza, Sugi Mukti, Muammar Rafsanjani.

puluhan tahun beroperasi di tanah Papua namun dianggap minim kontribusi terhadap pembangunan baik dari segi infrastruktur, pendidikan, dan kesehatan di tanah Papua itu sendiri.

2. Frame New York Times

New York times memuat berita yang berisi tentang isu pelanggaran Hak Asasi Manusia di Papua.

Tabel 3

Pelanggaran Hak Asasi Manusia dalam Konflik di Papua

Judul: 'Free Papua Movement' Intensifies Amid Escalating Violence (New

York Times, 12 Desember 2020)

\begin{tabular}{|c|c|}
\hline \multicolumn{2}{|c|}{ Frame: Pelanggaran Hak Asasi Manusia dalam Konflik di Papua } \\
\hline Framing Device & Reasoning Device \\
\hline Cathpharases: & Roots: \\
\hline $\begin{array}{l}\text { "Our rights have been violated } \\
\text { under international law," he said. } \\
\text { "Indonesia destroys not only my } \\
\text { people but our forests and our } \\
\text { mountains." }\end{array}$ & $\begin{array}{l}\text { Two years after Papuans declared } \\
\text { independence in 1961, Indonesia sent } \\
\text { troops to occupy the former Dutch } \\
\text { territory, and has maintained a } \\
\text { military presence ever since. In } 1969 \text {, } \\
\text { in a vote regarded by many Papuans as }\end{array}$ \\
\hline Depiction: & rigged, Indonesia rounded up a \\
\hline $\begin{array}{l}\text { Commerce in cities and towns is } \\
\text { dominated by non-Papuans while } \\
\text { many Indigenous Papuans eke out } \\
\text { a subsistence living in the region's }\end{array}$ & $\begin{array}{l}\text { thousand tribal leaders and held } \\
\text { them until they agreed to join } \\
\text { Indonesia. }\end{array}$ \\
\hline highlands, where many villages are & Consequences: \\
\hline accessible only on foot. The & Faced with such conditions, Ms. \\
\hline $\begin{array}{l}\text { Indigenous people have among the } \\
\text { country's lowest life expectancies } \\
\text { and infant mortality is high. }\end{array}$ & $\begin{array}{l}\text { Koman, the activist, said desperate } \\
\text { young people have joined rebel } \\
\text { groups in the jungle. "This vicious } \\
\text { cycle of violence needs to be stopped to }\end{array}$ \\
\hline Visual Images: & save the young generation of Papuans," \\
\hline $\begin{array}{l}2 \text { (dua) orang penduduk asli papua } \\
\text { yang sedang mengayuh perahu } \\
\text { tradisional di sungai dengan latar } \\
\text { rumah yang tidak layak. }\end{array}$ & $\begin{array}{l}\text { she said. "They will end up in jail or } \\
\text { fighting and sacrificing their lives." }\end{array}$ \\
\hline
\end{tabular}

Element inti berita (Idea Element), dalam pandangan New York Times, konflik di Papua yang syarat akan kekerasan dewasa ini adalah kristalisasi dari pelanggaran Hak Asasi Manusia yang selama telah dirasakan oleh penduduk asli Papua. Sejak menyatakan 
kemerdekaannya pada tahun 1961, Pemerintah Indonesia melakukan operasi militer di Papua. Pada tahun 1969 ketika terjadi referendum ribuan kepala suku dari berbagai suku dikumpulkan dan ditahan sampai mereka mau bergabung dengan Indonesia.

Hasil referendum itu disebut "The Act of Free Choice", dan setelah mendapat ratifikasi dari PBB maka sejak saat itu Papua Barat resmi menjadi bagian dari Indonesia. Kendati demikian, masih banyak warga Papua yang merasa daerah mereka diduduki secara paksa oleh Indonesia. Walaupun desakan untuk melakukan referendum ulang sempat meningkat namun Pemerintah Indonesia dengan tegas menolak karena keputusan hasil referendum pertama yang telah disahkan oleh PBB adalah final.

Sebagai pulau terbesar kedua di dunia setelah Greenland (denmark) Papua Barat memiliki sumber daya alam yang melimpah namun kekayaan tersebut tidak dirasakan oleh penduduk asli Papua. Papua Barat masih dinyatakan sebagai daerah paling terisolir dan undeveloved. Penduduk Papua memiliki angka harapan hidup terendah, serta angka kematian bayi tertinggi di Indonesia. Penduduk asli Papua sering mendapatkan perlakuan rasis dan diskriminasi dikarenakan penampilan mereka yang memiliki kulit gelap dan rambut keriting berbeda dengan penduduk Indonesia kebanyakan.

Perangkat pembingkaian (Framing Device) dalam struktur teks ini dipergunakan depiction dalam kutipan sebagai berikut:

Commerce in cities and towns is dominated by non-Papuans while many Indigenous Papuans eke out a subsistence living in the region's highlands, where many villages are accessible only on foot. The Indigenous people have among the country's lowest life expectancies and infant mortality is high. (New York Times, 12 Desember 2020).

Penggunaan kata Commerce in cities and towns is dominated by non-Papuans mencoba mengangkat perbandingan kesejahteraan penduduk pendatang dan penduduk asli Papua sebagai penekanan bahwa penyebab utama dari adanya gerakan pembebasan Papua dan kelompok kriminal bersenjata yang melakukan teror adalah karena adanya ketimpangan secara sosial.

Perangkat Penalaran (Reasoning Device), yang digunakan New York Times menggunakan strategi roots dalam kutipan berikut ini:

Two years after Papuans declared independence in 1961, Indonesia sent troops to occupy the former Dutch territory, and has maintained a military presence ever since. In 1969, in a vote regarded by many Papuans as rigged, Indonesia rounded up a thousand tribal leaders and held them until they agreed to join Indonesia. (New York Times, 12 Desember 2020).

New York Times memuat fakta akar permasalahan dari konflik di Papua sejak awal terjadinya referendum untuk memberikan parameter isu ke dalam isu Pelanggaran Hak Asasi Manusia agar tidak sampai masuk ke arah isu Nasionalisme. Ini menunjukkan adanya aspek kepentingan yang telah dilakukan oleh media massa dan hal ini sesuai dengan teori pendekatan konstruksi realitas (Berger \& Luckmann, n.d.) Peran media massa ternyata cukup besar, mengkonstruksi realitas dalam teks berita berdasarkan pemahaman yang tidak pernah vakum dari kepentingan, keberpihakan dan nilai-nilai. 
Rully Rozano Zarwan, Richie Petroza, Sugi Mukti, Muammar Rafsanjani.

Khalayak pembaca dan pendengar dengan setia memahami tanpa reserve, seolah sebagai realitas yang nyata mereka digiring kedalam frame atau bingkai yang dipasang oleh media. New York Times membingkai dengan aspek kepentingan tulisan sesuai kaidah Jurnalistik, karena dengan memberitakan Konflik di Papua, masyarakat internasional ingin mengetahui apa yang sedang terjadi di Papua di simbolkan dengan penduduk asli Papua yang terbelakang secara pengembangan sumber daya manusia serta Papua sebagai daerah kaya sumber daya alam yang undeveloved.

\section{Kesimpulan}

Dari liputan peristiwa-peristiwa Konflik Kelompok Kriminal Bersenjata di Papua adalah realitas atau peristiwa yang dimaknai secara berbeda oleh Kompas dan New York Times, kedua media dipengaruhi oleh karakteristik-karakteristik masing-masing, begitu pula dalam melakukan pengemasan dan pembingkaian berita terhadap realitas Konflik Kriminal Bersenjata di Papua. Menggunakan analis Framing Gamson dan Modigliani bahwa realitas yang terjadi dalam perangkat framing divice dan reasoning divice. Kompas mengemas bahwa konflik Kelompok Kriminal Bersenjata di Papua dapat diselesaikan melalui jalan persuasif yaitu dialog yang melibatkan tokoh-tokoh masyarakat di Papua dengan Kelompok Kriminal Bersenjata, sementara New York Times mengemas dalam pandangan yang berbeda, konflik Papua adalah kristalisasi adanya pelanggaran Hak Asasi Manusia yang sudah lama terjadi kepada penduduk asli Papua. Dari segi nara sumber atau objek yang dijadikan berita juga berbeda, New York Times lebih cenderung mengambil dari nara sumber yang berada dalam pihak yang pro dalam pembebasan Papua Barat sementara Kompas, cenderung menggunakan narasumber yang berasal dari Pemerintah Indonesia. Fakta dan data ini yang menunjukkan bagaimana kepentingan sebuah realitas atau peristiwa Konflik Kelompok Bersenjata di Papua dimaknai secara berbeda oleh dua Media. 
Analisis Framing Media Kompas dan New York Times Terhadap Pemberitaan Konflik Kelompok Kriminal Bersenjata di Papua

\section{Bibliografi}

Berger, Peter L., \& Luckmann, Thomas. (n.d.). Tafsir Sosial Atas Kenyataan. 1990. Jakarta: LP3ES.

Dida, Fernanda Raka Kusuma. (2017). Strategi Integrated Marketing Communication Endank Soekamti (Studi Deskriptif Kualitatif Terhadap Strategi Promosi Endank Soekamti Sebagai Band Indie). Universitas Brawijaya.

Hidayat, Dedy N. (1999). Paradigma dan Perkembangan Penelitian Komunikasi. Jurnal Ikatan Sarjana Komunikasi Indonesia, 3(4), 24-26.

Littlejohn, Stephen W., \& Foss, Karen A. (2010). Theories of human communication. Waveland press.

McQuail, Dennis. (1994). Teori komunikasi Massa: PT. Gelora Aksara Pratama.

Moleong, Lexy J. (2012). Metodologi Penelitian Kualitatif, Bandung. Pariwisata Pedesaan Sebagai Alternatif Pembangunan Berkelanjutan (Laporan Penelitian Hibah Bersaing Perguruan Tinggi) Yogyakarta.

Mulyana, D. R. Deddy. (2002). ANALISIS FRAMING Konstruksi, Ideologi, dan Politik Media. LKIS PELANGI AKSARA.

Muslim, Muslim. (2013). KONSTRUKSI MEDIA TENTANG SERANGAN ISRAEL TERHADAP LIBANON (Analisis Framing terhadap Berita tentang Peperangan antara Israel dan Libanon dalam Surat Kabar Kompas dan Republika). Jurnal Studi Komunikasi Dan Media, 17(1), 75-92. http://dx.doi.org/10.31445/jskm.2013.170104

Rusadi, Udi. (2002). Diskursus Kerusuhan Sosial Dalam Media Massa. Disertasi Dalam Bidang Ilmu Komunikasi, Universitas Indonesia.

Santosa, Bend Abidin. (2017). Peran media massa dalam mencegah konflik. Jurnal Aspikom, 3(2), 199-214.

Shoemaker, Pamela J., \& Reese, Stephen D. (1996). Mediating the message. White Plains, NY: Longman.

Sobur, Alex. (2001). Analisis Teks Media; Suatu Pengantar Untuk Analisis Wacana, Analisis Semiotik, Analisis Framing. 